\title{
Coming Into Mindfulness: A Practice of Relational Presence to Cultivate Compassion in One Rural School
}

\author{
Sonal Kavia and M. Shaun Murphy
}

\begin{abstract}
This narrative inquiry explores personal and professional stories of two educators, nurtured and supported by their school leadership, in a rural school setting, who have had diverse experiences with the contemplative practice of mindfulness. Our research primarily focused on the following wonders: How does the experience of mindfulness practice shift teacher identity and awareness, and the quality of time educators spend with children and youth? As educators, how can the practice of mindfulness expand our experience of listening, loving kindness, and compassion within educational spaces? We explore how their unique experiences of mindfulness are woven into the fabric of their school and a mindful pedagogy.
\end{abstract}

\section{Vignette A Warm Welcome}

The soft and playful flowers on the wall welcomed me into the front doors of the school. Not sure what to expect, I felt compelled to move slowly into the small circular entrance where I see three words on a plant pot:

grateful, thankful, blessed

My head turned, and what I saw next was a beautiful visual canvas sharing an artful definition of the word 'family',

family: people who share a common start and grow to share a common heart.

I instantly shared my feeling with Shaun, my coresearcher; a feeling of warmth one often feels when they are home. I even said it already reminded me of the sanctuary of the schools I had once worked in with kindred spirit educators in the distant past. My heart space felt open so quickly in this new space and I remember saying, "My people are here!"

A few moments later, down the hall, on the way to the gym, the principal smiled and said to one of the children, "This is my new friend Sonal," I felt welcomed.

At the gym, we met a young man who regularly practiced mindful yoga with the children. There was giggling and smiles and high fives as the kids walked in and found their space. The process of arriving in the gym seemed soft and joyful. The first to come patiently waited as the last ones trickled in. The principal welcomed all adults and children with her smile and found her seat also on the floor with the children. I remember smiling at this unfolding process. 
The mindfulness teacher rang the bell, invited us to close our eyes and take a deep breath. I witnessed a slight raise in the chest of many children around me as their lungs expanded, and then the deep let down of the chest and shoulders. I remember feeling my own shoulders relax and shift down away from my ears, as the children relaxed. There was a collective sigh and I remember feeling a sense of peace as I became aware of my breath.

It was clear, the intention was to make children and community members feel welcome. It occurred to us that the symbol of a flower invites young people to come in and bloom. Even strangers like us, upon entering the school, know that there is something kind here, something seemingly soft and nourishing. The ease we felt coming into this place was unusual. Seeing the words "thankful, grateful, blessed" alongside a definition of "family" offered the sense that connectedness was important here.

Sonal was careful and cautious as she and Shaun spent time in the front entrance. This was a mindful way to enter, whether into a building or into an experience with another person. As we moved into an unknown environment, we observed the language of space, the power of words, and the actions of others to make sense of that which we once did not know. Inside this rural school, in which this narrative inquiry unfolded, we instantaneously felt welcomed and at home. As visitors, any caution and care quickly turned into curiosity and intrigue. Sonal realized she moved slowly and carefully, when she moved from outside/outer to inside/inner spaces. The power of language all over the walls and the behavior of the principal, secretary, staff, and children all set an inclusive tone for the visit.

The mindfulness experience in the gym, involving the whole school, had us in the most intimate of explorations, breathing life force slowly in and out of our bodies in a kind and gentle way. A gathering this big, and in this way, is a significant happening, especially in this mindful way of learning to breathe together. lyengar (1999) stated that, Pranayama, a breathing practice, "is a conscious prolongation of inhalation, retention and exhalation" (p. 10) and that "the practice of Pranayama develops a steady mind, strong will-power and sound judgment" (p. 10). Sitting and breathing brought us all together in a moment of time. Hanh (2015) suggested, "when we breathe mindfully, we reclaim our territory of body and mind and we encounter life in the present moment" (p. 17). Sonal's first impression and observation of this school was certainly affected by the commitment of the leadership and staff to the development of the whole lives of the children. Their actions were reaching towards wellness for themselves and the children.

In her own teaching and learning journey, Sonal had come into mindfulness years before while teaching at an elementary school in an urban centre. She had been exploring breath awareness and yoga in her personal life when the principal at her school sent out a short clip about mindfulness in schools to all the teachers. The principal had been developing an understanding of how to nurture teachers to experience such practices for themselves and, furthermore, to understand how children's well-being might be enhanced. At that time, in her work, Sonal was considering how to nourish the inner awareness of children, because she realized that outer awareness was predominantly encouraged. Sonal realized that teachers often lack the ability, time, experience, and education to honor children's experience in a holistic manner. She began to learn what mindfulness was and why it mattered in education. 


\section{What Is Mindfulness?}

As she developed an understanding of mindfulness, Sonal came to increase her own practice of bringing her attention into the present moment. Kabat-Zinn (2005) shared that mindfulness can be thought of as, "an openhearted, non-judgmental, present-moment awareness, the direct, non-conceptual knowing of experience as it unfolds, in its arising, in its momentary lingering, and in its passing away" (p. 128). Barbezat and Bush (2014) suggested that, "mindfulness is being aware in the present moment, not judging but accepting things as they are" (p. 98). Over time, Sonal realized she felt more present and attuned to others and her environment. She also felt more connected to her breath. Sonal felt the quality of her personal and professional relationships became significantly more meaningful. The following quote by Kabat-Zinn (2013) highlights the true essence of mindfulness:

When we speak of mindfulness, it is important to keep in mind that we equally mean heartfulness. In fact, in Asian languages, the word for "mind" and the word for "heart" are usually the same. So if you are not hearing or feeling the word heartfulness when you encounter or use the word mindfulness, you are in all likelihood missing its essence. (p. xxxv)

Murphy-Shigetmatsu (2018) suggested that a mainstream image of mindfulness is "that it means being self-centered, yet we can better reframe our inner work as a collective, communal, and connected way of being" (p. 13). The harmony of inner experience with outer awareness leads to a sense of well-being that can be holistic, preventative, integrative, and compassionate (Yeager \& Howle, 2013). We realized our research school had undergone changes over time and they were trying to prevent children, teachers, staff, and people in the community from feeling disconnected. They had been building a language of mindfulness based on the experience and understanding of the principal and wellness educator, and felt kindness and compassion was central to their community building. In our multiple visits to this school, we witnessed and became familiar with the diverse layers of experience and intentions of the research participants and how they came into mindfulness.

\section{Here We Are...In This Place}

Sonal came to understand that this small rural school, G. F. Meyer Elementary, ${ }^{1}$ two hours away from a major city centre, was home to leadership and a group of educators who based their learning and teaching in the practice of mindfulness. By the end of the first day of Sonal's initial visit, she had had conversations with two educators and the principal. Although the encounters were brief that first day, Sonal recognized the diversity of experience with mindfulness that the participants possessed. The place reflected a quality of interrelatedness of a thoughtful group of people. A young teacher (Russell), the wellness educator (Willa), and the principal (Patti) shared their unique story of coming into mindfulness. This narrative inquiry primarily wondered about the experiences of Russell and Willa, inquiring into how each of them came into this practice and way of being. We briefly share details of the principal, Patti, to give a richer picture of the supportive nature of the leadership at the school. Additionally, conversations with other staff members formed a fuller picture of how changes took place at this school over time. 
G. F. Meyer Elementary School is a home for 199 kindergarten to grade 6 children and 26 staff. There are 15 teachers who teach in 11 classrooms. It is a small community-based school with a strong sense of inclusion, connectedness, and relationship building. The children at the school enjoy a wide diversity of experiences as a result of the generous vision of a leadership and staff who aim to make well-being a part of their careful work. Sonal smiled much of the time as she observed, interacted, and took part in the happenings of the day.

\section{Understanding Beginnings}

As Sonal spent more time with the research participants, Patti, Willa, and Russell, it was clear that significant, thoughtful attention was being placed in the environment, the learners, and teachers. It became evident that a commitment was made to learning about mindfulness and to engaging in practices of mindfulness. A language and dialogue around mindfulness had been built over time with teachers, administrative staff, caretakers, and the larger community. All members of this community engaged and stepped into the process as they felt comfortable.

Patti, the principal, seemed especially gifted in the art of creating a safe and comfortable space for explorations for the educators, staff, and children in the school. She was strong, energetic, and loving. In a first interview regarding mindfulness, she exclaimed that she could see the possibilities of mindfulness and a mindful way of being in her personal and professional life, and we spoke of unconditional love in leadership. Patti's message to her staff, and especially the young teachers, was, "that I will love you no matter what, and I know there is going to be hard days, whatever I can do to help, I will help. I tell them it will all work out" (Patti, March 9, 2018). Her vision grew and expanded from inside out, and she definitely wanted her "family" at the school to feel supported by her. We found out that, over time, the school came to flow more easily at a relational, pedagogical, and communal level as mindfulness was explored over numerous years. Personal and professional explorations of our research participants affected the happenings in the day-to-day lives of adults and children at the school. Our research interests in these personal and professional shifts were guided by narrative inquiry research.

\section{The Narrative Inquiry Method}

This research was designed to gather the storied experiences of teachers and an administrator who came into mindfulness on a personal or professional landscape. Narrative inquiry, the research methodology used within this study, is, as suggested by Connelly and Clandinin (2006), "the study of experience as story" (p. 477). The stories of the research participants, as told through interviews and dialogue, provided a base for understanding the experience of the participants and the school community from the "three commonplaces of narrative inquiry - temporality, sociality, and place" (p. 479). These three commonplaces allow an understanding of each participant in a holistic and expansive manner. Temporality, having to do with the notion of time, allows the researcher to understand participants' lives as in a process of change, and flowing between past, future, inward, and outward, "simultaneously in 
these four ways" (Clandinin \& Connelly, 2000, p. 50). Sociality, having to do with relationship, attends to the personal and social situations of both the participant and researcher (Connelly \& Clandinin, 2006). Lastly, place has to do with the location in which the experiences occurred. Connelly and Clandinin (1999) viewed place as storied and "having a history with moral, emotional, and aesthetic dimensions" (p. 2). Clandinin and colleagues (2013) shared that narrative inquiry allows for inquiry into the lived experiences of participants, and may also be attentive to "social, cultural, linguistic, familial, and institutional narratives" (p. 45). Finally, in a narrative inquiry, we try to understand significant personal, practical, and social justification (Clandinin \& Huber, 2010). We, as researchers, engage in the questions "So what" and "Who cares?" to understand why this particular narrative inquiry research can be significant on a wider societal level (Connelly \& Clandinin, 2006).

Sonal's original research puzzle questioned: How does the experience of mindfulness practices shift teacher identity and inner awareness and promote compassionate educational communities? She was interested in the quality of time spent with children and youth, and the relational aspects of listening, loving kindness, and compassion within that time. The three commonplaces of time, sociality, and place unfolded within our inquiry in which the participants told their stories during five visits over five months. In listening to the stories of the participants, these questions developed our understanding of their experiences as related to our research puzzle: How did Russell and Willa come into mindfulness? How did they come into new understandings and ways of being? What was it about them that was making relationships flow and bloom at the school?

In their personal lives or within the school landscape, Russell and Willa had come into an understanding or experience of mindfulness in their own way and at significantly different times or circumstances in their professional lives. Each participant storied their experience, and within those stories an understanding of the tensions that affected their identity and awareness became clear. Clandinin et al. (2010) suggested these are the stories of "who they are and who they are becoming as they interact with children" (p. 82) and shared that they came "to see tension as a central component in understanding the experience of people in relationship" (p. 88). In hearing the stories of the participants, similar and variant threads of the participants' experiences of coming into mindfulness emerged, as did the tensions each felt with their new and growing knowledge, a blend of the personal and the professional. This combination of the personal and practical is understood by Connelly and Clandinin (1988) as personal practical knowledge, which is described in the following manner:

[lt is a] term designed to capture the idea of experience in a way that allows us to talk about teachers as knowledgeable and knowing persons. Personal practical knowledge is in the teacher's past experience, in the teacher's present mind and body, and in the future plans and actions. Personal practical knowledge is found in the teacher's practice. It is, for any teacher, a particular way of reconstructing the past and the intentions of the future to deal with the exigencies of a present situation. (p. 25)

The participants told of impacts on their lives personally and professionally and it became apparent that their "personal practical knowledge" (Connelly \& Clandinin, 1988, p. 25) had changed the landscape of their school. The unique tensions that were present in each participants' journey of coming into 
mindfulness were catalysts for shifts in identity, knowledge, and awareness. These tensions encountered by each participant were important in how their personal practical knowledge unfolded. In telling their stories, considerations of sociality, temporality, and place are given attention (Connelly \& Clandinin, 2006), as are the tensions they experienced.

\section{Russell}

Russell, a young beginning teacher, was hired the day he finished his practicum in Eastern Canada. When asked about his introduction to mindfulness, he said it was the principal that introduced it to him one August afternoon when they met in person for the first time. He had not heard of mindfulness before he came into his work as a beginning teacher.

He was in his third year as a classroom teacher at the time of our first interview. At Russell's first interview, we asked him what his understanding of mindfulness was, and he responded that he would now describe it as, "in the most basic terms, and like I said, this is constantly changing for me, just being in the present moment and being aware" (Russell, March 9, 2018). As we interacted with Russell, it was apparent that he was deepening his knowledge and experience of mindfulness practices with support. We observed that Russell was open, eager to share, and thoughtful while sharing his experiences about how he came to know about mindfulness, new understandings of curriculum, and his own shifts, as he moved through his first years of teaching.

\section{Understanding Mindfulness as Unspoken Curriculum}

We recognized a tension of teaching mindfulness in relation to mandated subject matter. Early that first year while going through his timetable, Russell noticed a block for mindfulness time. He engaged in a conversation with his principal inquiring into what mindfulness was and why they included this practice in their school day. Driven by provincial government mandated curriculum, Russell had many questions.

Russell shared that during his early teaching days his time was "purely allotted to curriculum" (Russell, April 19, 2018). He would teach right up until the bell and felt he had to use all the time to teach the mandated curriculum. Russell found the concept of mindfulness abstract, which posed a nervous tension around teaching it to students. It was beneficial for him to have the wellness educator, Willa, come into his class to teach these sessions. Russell was reflective after these sessions in which the wellness coordinator worked with the children. He was developing his ideas of how these practices might be valuable to children:

If we can slowly introduce this to kids it will be so important in understanding their emotions or feelings, kindergarten all the way to grade 6 here, and they can slowly pick up the pieces. It's going to be so important to them...being in the present moment, it could be huge for them, especially with all these problems going on right now, I think with bullying or mental illness, or whatever right? (Russell, April 19, 2018) 
Russell understood why the principal, coordinator, and other staff were working towards a language of mindfulness at the school and his idea of curriculum was evolving over time. There were both small ways and big ways that shifts had happened for him. In the classroom, it was in the way he felt more relaxed about what he felt should be happening and allowing things to unfold as they did. Russell had shared that he saw his relationships in the classroom and in his personal life change over time. He was clear that he had noticed the way that he responded to others was evolving in his classroom and even in his personal life with his family.

Understanding how to best bring curriculum to life in the classroom is a challenge and journey for any new teacher. Russell's idea of what to teach and what not to teach was changing. He shared, "there were more important things to teach than the curriculum at times" (March 9, 2018). The more he was referring to has been highlighted by theorists as "implicit" or "hidden curriculum" (Inlay, 2016, p. 24), "inner curriculum" (Ergas, 2018, p. 78), and "curriculum-as-lived-experience" (Aoki, 1986). Inlay (2016) stated, "every school has an implicit curriculum of messages sent by every structure and process, and by every person in the school's environment" (p. 24). When a school or educator also takes time with an inward focused curriculum, it can privilege what Owen-Smith (2017) described as "connected knowing, interiority, and engagement with the self and others" (p. 25). In this new time of coming into and making meaning out of mindfulness practices, classroom management, and making connections within curriculum, there was a period of becoming for Russell. He was becoming familiar with a wider, more expansive life curriculum. He was also becoming less driven by provincially mandated curriculum, noticing growth in his own capacity to be empathetic and compassionate.

\section{Slow Evolution-Shifting into Compassion and Empathy}

Russell's ideas of what a classroom and a school should be began to change over time. He experienced tensions around what a traditional classroom or school should look like. When asked the question: "What if you didn't find mindfulness?", Russell answered:

Well, I certainly know, the type of teacher I would be, I would be a very, for lack of better words, a traditional teacher. You know we would be sitting in our desks, there would not be tons of collaboration, there would not be flexible seating, it would be 'sit down - be quiet' you have a job to do. (Russell, March 9, 2018)

Russell felt he was developing a greater relational capacity to empathize and care for the children because of his mindfulness experiences. He shared,

[a] shift has happened, by being mindful, and being aware and empathizing and caring...three years ago, I would have said the most important part of teaching is connecting with the curriculum... and that shifted for me and I honestly believe it is because of the building I am in. I'm not saying teaching curriculum is not important, but I think giving students what they need is sometimes more important. (Russell, March 9, 2018)

Burrows (2011) stated, "relational mindfulness can help educators to address the management, teaching, and emotional challenges of classroom and school environments more successfully" (p. 24). Kyte's (2016) 
suggested, "with teachers gaining inner strength, they become more present and responsive to their students' needs, thus becoming more effective teachers, role models, and guides to healthy behaviors" (p. 1147). What we learned from Russell is that mindfulness is a way of attending to the child. The other things are extras and not the focus of Russell's work with mindfulness. Through his words we came to understand that this work helped him pay attention to their lives, and curriculum then became something more than a sole focus on subject matter.

Russell grew through the challenge of questioning the un-traditional mindfulness blocks; he continued to participate in the mindfulness sessions that were offered to his class; and he began to take part in staff professional development, some of which involved mindfulness sitting practice and a weekly staff gathering for gratitude practice. In the following passage, Russell remarks on the support that he received from the principal:

Then it slowly started to evolve into what it means to me. As [the principal] gave us PD or we practiced with our kids, it's something that is ever changing for me. Something that has actually become very important in my classroom actually, which I would have never said three years ago. (Russell, March 9, 2018)

Russell shared about shifts he noticed in himself as time went by. He noticed how others worked with mindfulness practices and saw that the school had become a place of compassion. Bai and Cohen (2007) highlighted that educators "teach others by being an authentic and living embodiment of what they deem to be valuable and potentially meaningful to learners" (p. 52). Inlay (2016) shared that, "the affective and overt behaviors of individuals within the school's culture, convey messages of the implicit or hidden curriculum of a school that subtly but powerfully influence the school's culture" (p. 23). As a researcher attentive to the impact of the introduction of mindfulness on a beginning teacher in a school, wonders arose for Sonal: What if Russell had been introduced to mindfulness practices during the course of his higher education experience in university? What if he had the opportunity to explore and embody a practice before he began teaching? Russell was just one participant that shifted the essence and fabric of the school. He acknowledged his experience was affected by another research participant, Willa, the wellness coordinator, who role-modeled mindfulness experiences with the children in his classes.

\section{Willa}

Willa holds the wellness coordinator role at the school and collaborates with the teachers and leadership to integrate possibilities for wellness experiences for children and adults. Of the three research participants, Willa has been at the school the longest and works closely with Patti, the principal, in building the culture of the school. Her position arose historically out of a need that the local school board deemed important. Wellness coordinator positions were created for many schools within that division. In Willa's 10 years, she has been able to observe changes in her role and the school, in her words, "evolve over time" (Willa, March 9, 2018). There were times when she was unsure of what this role should look like. 
Willa began a personal contemplative meditation practice nine years prior to our conversations with her. A mindfulness practice had benefited her personal life in various ways, and she recognized possible benefits to young people. She explained that to her, mindfulness was like "a process and journey for oneself in kind of being gentle with yourself everyday" (March 9, 2018). A tension in Willa's story involved her questioning how she could meaningfully bridge her personal learning of mindfulness and meditation into her professional offerings. Connelly and Clandinin (1999) "developed the notions of personal practical knowledge and professional knowledge landscape, both narrative educational concepts, as a way of understanding teacher knowledge" (p. 3). Willa shared, "for me it's so intertwined, I can't just talk in a school sense, because they intertwine" (Willa, March 9, 2018). She was expressing that her ways of being in personal contexts and professional contexts were weaving into each other. Willa was questioning how what she knew [her mindfulness practices and learning] informed her teaching practices and her identity as a teacher. In the following interview excerpt, when asked what the value of the practice was for her, she tells us that her practices of mindfulness are connected to her identity:

I guess because I feel like if I don't practice my life is going to get out of control! [laughs]. So maybe it is not a hard question, it's a simple answer. I don't think I can rate it, or put it on a scale because it has just become who I am. I can't even say that I have, it's just a part of me. (Willa, March 9, 2018)

Willa is situated in a supporting and impactful role and her relationships with teachers and children have changed over time. Clandinin et al. (2013) suggested that lives are composed as a process of change, involving the "temporal unfolding of their lives in different places and in different relationships" (p. 48). Willa expressed that her relationships, with regards to herself and others, had shifted as a result of coming into mindfulness. Although she does not recall the moment she was introduced to mindfulness, she shared, "I have seen a big shift...that my role has shifted" (Willa, March 9, 2018). Goldman-Schuyler et al. (2017) stated, "a radical shift is needed for most people to develop a conscious, sustained effort toward being mindful in the context of work" (p. 87). Willa shared that a significant personal shift happened in her experience of taking a Mindful Schools course online. She began identifying herself within the school as someone who could share some of the practices. Willa was developing a "story to live by" in the context of her school (Connelly \& Clandinin, 1999, p. 4). A story to live by refers to identity and is "given meaning by the narrative understandings of knowledge and context" (p. 4). When asked, "What if you didn't find mindfulness?", Willa shared: "I would be, you know, constantly searching for something, and with this practice I don't feel like I'm searching for anything in this job, I really feel like mindfulness is such a base foundation" (Willa, March 9, 2018).

Willa was finding purpose in the practices of mindfulness to inform her time with children. Byrnes (2012) stated, "teachers' transformative experiences have the potential to develop and enhance their ability to teach with compassion, integrity, and mindful awareness" (p. 25). Willa was developing her understanding of how mindfulness could be a base foundation from which to engage, and she highlighted deep listening as beneficial to her teaching journey. 


\section{Deep Listening... Receptivity}

Willa's significant shift in deep listening strengthened her attunement to others. Siegel (2017) shared, "interpersonal attunement is the focusing of kind attention on the internal subjective experience of another" (p. 227) and "two differentiated individuals to become linked in that moment as a we" (p. 228). Willa was deepening her connection to others and her moment-to-moment awareness was her practice. Barbezat and Bush (2014) stated, "deep listening is a way of hearing in which we are fully present with what is happening in the moment without trying to control it or judge it" (p. 137). Willa said, [mindfulness] offers her the tools to "be responding instead of reacting" (Willa, March 19, 2018) within her personal and school relationships. She further told us that being responsive versus reactive, "was like a practice to me, a practice of deepening my listening practice." (Willa, March 9, 2018). She felt adults and children would benefit as she herself had benefited from a mindfulness practice that gave her tools and strategies that were empowering for her to listen well within her life relationships. Willa's personal practice consisted of practicing meditation both by herself and in community (she lived in a neighboring city) and to continue to explore being open and present in her daily interactions. Willa said that, over time, she has noticed her ability to respond versus react had grown. She and the principal of the school were exploring mindfulness through personal experience and practice, books, and each other. There was no local community group offering a gathering to practice mindfulness meditation. She identified this deep listening as something that contributed to her receptiveness in her school relationships. Hruska (2008) described being receptive as entailing, "being still, open, looking, listening, perceiving, and waiting" (p. 32). Development of receptivity, which is a slow process, often involves a deep listening when reflecting both outwardly and inwardly. Willa recognized receptivity as important for both adults and children in the culture of the school.

\section{Vignette-Inner Voice in Education}

I followed Willa to her small office attached to the library. I noticed a lamp was lit and there were pictures on the walls. There were books on peace and mindfulness on the counter. It was quiet. It felt like a place to pause and seemed a quiet sanctuary within the school. As we sat together, she shared that she felt like children need to have time to spend with themselves. She explained that she herself had spent much time listening for her own inner voice in this space and wanted this to be a space for the children to do the same.

Willa described her intentions to hold space so that children can have time for quiet reflection. Willa shared the following,

We are always telling kids to go find an adult, and talk about things, and that is a great strategy, but I really feel like kids need to start spending time with themselves, reflecting and listening to that inner voice that I feel we don't talk about in education. (Willa, March 9, 2018)

She saw herself as a means to which some of the children would have "a chance to listen to their inner voice" (Willa, April 19, 2018). Willa's story involved the tension of something missing in our educational spaces. She alludes to the sense that our inner voices are not attended to, acknowledged, or given space. She shared that, "mindfulness practice gives answers or ease maybe to the internal dialogue or the 
internal struggles" (Willa, April 19, 2018). Byrnes (2012) reminded us, "contemplative education begins with the most intimate relationship possible_relationship with oneself" (p. 36) with a movement "both outward into the world and inward into one's own mind, body and heart" (p. 37).

Willa was attending to her own inner voice by being receptive and deepening her listening abilities. We observed that she was reaching towards whole experiences for the young and trying to create space within the context of her professional offerings. Willa was engaging in her own personal and professional development by honoring the ontological question: why is contemplative pedagogy important for holistic education? Willa recognized, from her own experience, the importance of "teaching kids more about themselves as a whole" (Willa, May 16, 2018) and being a facilitator for experiences to unfold for young people which encourage "social and emotional needs" (Willa, April 19, 2018) and well-being. The harmony of inner experience with outer awareness leads to a sense of well-being that can be holistic, preventative, integrative, and compassionate (Yeager \& Howle, 2013). Willa shared her understanding that children and others want to be around "somebody who is calm and somebody who is not going to react to what's being said in that moment and that builds that trust" (Willa, April 19, 2016). Her intuition and intent were strong in her explorations with mindfulness practices and her impact on the development of these practices within the culture of the school.

\section{Profundity of the Gift of Compassionate Presence}

We realized what these research participants had come into by expanding their experience of mindfulness. It was presence. The participants themselves did not use the word presence to describe their experiential evolution. Rather, these words came to us as we stepped back to consider common threads in their stories and experiences. Compassion and receptivity were common threads. This presence we speak of here was the expression of the unique effect of mindfulness practices that each had experienced over time. A profundity of the gift of compassionate presence is that mindfulness is not being reached for or sought out as an integration into the school, but rather that it is an embodiment of various qualities of awareness by the very people that bring the space alive.

Merriam-Webster's (2011) Canadian dictionary defines presence as "the fact or condition of being in a certain place" (p. 330) Connelly and Clandinin (1999) suggested, "matters of professional identity are intimately interwoven with spatial and temporal borders on the professional knowledge landscape" (p. 112). We realized the research participants had both spoken about the spaces of their classrooms and the unfolding of their awareness over time. Rodgers and Raider-Roth (2006) defined this "presence in teaching" as

a state of alert awareness, receptivity, and connectedness to the mental, emotional, and physical workings of both the individual and the group in the context of their learning environments, and the ability to respond with a considered and compassionate best next step. (p. 265).

Boccio (2004) described mindfulness as a "lived understanding" (p. 20) and goes on to share that compassion is cultivated so that there is "no sense of separation" (p. 20). Teachers in this compassionate 
presence would see themselves in others and recognize their connectedness to others. The experience of coming into mindfulness occurred for both these participants after they began their practical knowledge building in the classroom and school. They were both given the space and time to attend to the nuances of cultivating compassion, receptivity, and presence into the school culture. The qualities of deep listening, present moment awareness, direct perception, and empathy are imperative for enriching our teaching and learning spaces. The teacher participants in this inquiry, with the pillar of support of the leadership, were given the opportunity to experience and explore a relational mindful pedagogy.

\section{Conclusion}

This small rural school has become a positive centerpiece of the community as a result of experiential shifts. The participants have grown and developed in ways that contributed to a common language or foundation of mindfulness. It was beneficial to have the opportunity to engage with both a seasoned teacher practitioner and a beginning teacher. It is worthwhile to continue investigating our wonders: What if beginning teachers were introduced to mindfulness practices during the course of their higher education experience in university in a safe and supported way? What if they had the opportunity to explore and embody a practice before they began teaching? University and college teacher education classes, which include an understanding and practice of mindfulness, would allow for a platform for insight and growth before young teachers figure out "a way of relating that requires time, attention and care" (Schneider \& Keenan, 2015, p. 12). The shifting identities of these teacher participants over time create the possibility that mindfulness practices can have an impact, not only on the lives of children and adults, but also on the culture of a school.

\section{Note}

1. All names of places and people are pseudonyms.

\section{References}

Aoki, T. T. (1986). Teaching as in-dwelling between two curriculum worlds. The B.C. Teacher, 65(3), $8-10$.

Bai, H., \& Cohen, A. (2007). Breathing qi (ch'i), following dao (tao): Transforming this violence-ridden world. In E. Eppert \& H. Wang (Eds.), Cross-cultural studies in curriculum (pp. 35-54). Lawrence Erlbaum.

Barbezat D. P., \& Bush, M. (2014) Contemplative practices in education: Powerful methods to transform teaching and learning. Jossey-Bass.

Boccio, F. J. (2004). Mindfulness yoga: The awakened union of breath, body, and mind. Wisdom Publications. 
Coming Into Mindfulness: A Practice of Relational Presence to Cultivate Compassion in One Rural School

Burrows, L. (2011). Relational mindfulness in education. ENCOUNTER: Education for Meaning and Social Justice, 24(4), 24-29.

https://www.academia.edu//1299863/Relational_mindfulness_in_education

Byrnes, K. (2012). A portrait of contemplative teaching: Embracing wholeness. Journal of Transformative Education, 10 (1), 22-41. https://doi:10.1177/1541344612456431

Clandinin D. J., \& Connelly, F. M. (Eds.). (2000). Narrative Inquiry: experience and story in qualitative research. John Wiley \& Sons, Inc.

Clandinin, D. J. \& Huber, J. (2010). Narrative Inquiry. In B. McGaw, E. Baker \& P.P. Peterson (Eds.), International encyclopedia of education (3rd ed.) (pp. 1-26). Elsevier.

http://www.mofet.macam.ac.il/amitim/iun/CollaborativeResearch/Documents/Narrativelnquiry.pdf

Clandinin, J. D, Murphy, M. S., Huber, J., \& Orr, A. M. (2010). Negotiating narrative inquiries: Living in a tension-filled midst. The Journal of Educational Research, 103, 81-90.

Clandinin, D. J, Steeves, P., \& Caine, V. (2013). Composing lives in transition: A narrative inquiry into the experiences of early school leavers. Emerald.

Connelly, F. M., \& Clandinin, D. J. (1988). Teachers as curriculum planners: Narratives of experience. OISE Press.

Connelly, F. M., \& Clandinin, D. J. (1999). Shaping a professional identity: Stories of educational practice. Teachers College Press.

Connelly, F. M., \& Clandinin, D. J. (2006). Narrative inquiry. In J. Green, G. Camili, \& P. Elmore (Eds.), Handbook of complementary methods in education research (pp. 375-385). Lawrence Erlbaum.

Ergas, O. (2018). Schooled in our own minds: Mind-wandering and mindfulness in the makings of curriculum. Journal of Curriculum Studies, 50(1), 77-95.

https://doi.org/10.1080/00220272.2017.1363913

Goldman-Schuyler, K., Skjei, S, Sanzgiri, J., \& Koskela, V. (2017). "Moments of waking up": A doorway to mindfulness and presence. Journal of Management Inquiry, 26(1), 86-100.

https://doi.org/10.1177/1056492616665171

Hanh, T. N. (2015). This moment is full of wonders. Chronicle Books LLC.

Hruska, Barbara (2008). The receptive side of teaching. Kappa Delta Pi Record, 45(1), 32-34. https://doi.org/101080/00228958.2008.10516529

Inlay, L. T. (2016). Creating a culture of respect through the implicit curriculum. Middle School Journal, 47(2), 23-31. https://www.jstor.org/stable/24637777

lyengar, B.K.S (1999). Light on pranayama: The yogic art of breathing. The Crossroad Publishing Company.

Kabat-Zinn, J. (2005). Coming to our senses: Healing ourselves and the world through mindfulness. Hyperion.

Kabat-Zinn, J. (2013). Full catastrophe living. Bantam Books. 
Kyte, D. (2016). Toward a sustainable sense of self in teaching and teacher education: Sustainable happiness and well-being through mindfulness. McGill Journal of Education, 51(3), 1143-1162. https://id.erudit.org/iderudit/1039632ar

Merriam-Webster. (2011). Presence. In Webster's Canadian dictionary for school, home and office.

Murphy-Shigematsu, S. (2018). From mindfulness to heartfulness: Transforming self and society with compassion. Berrett-Koehler Publishers, Inc.

Owen-Smith, P. (2017). Reclaiming interiority as place and practice. In D. Shannon \& J. Galle (Eds.), Interdisciplinary approaches to pedagogy and place-based education (pp. 23-35). https://doi:10.1007/978-3-319-50621-0_3

Rodgers, C. R., \& Raider-Roth, M. B. (2006). Presence in teaching. Teachers and Teaching: Theory and Practice, 12(3), 265-287. https://doi.org/10.1080/13450600500467548

Schneider, D. A., \& Keenan, E. K. (2015). From being known in the classroom to "moments of meeting": What intersubjectivity offers contemplative pedagogy. The Journal of Contemplative Inquiry, 2(1), 1-16. http://journal.contemplativeinquiry.org/index.php/joci/article/view/28

Siegel, D. (2017). Mind: A journey to the heart of being human. W.W. Norton \& Company Inc.

Yeager, A., \& Howle, S. (2013). Teaching peace and wellness as the wisdom path. In J. Lin, R.L. Oxford \& E.J. Brantmeier (Eds.), Re-envisioning higher education: Embodied pathways to wisdom and social transformation (pp. 125-141). Information Age Publishing.

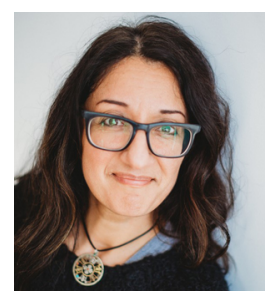

Sonal Kavia is an education consultant who resides in Saskatchewan, on Treaty Six territory. Her work focuses on individual, relational, and collective well-being. After teaching in her own classroom for several years, she has shared well-being strategies with youth and adults in K-12 schools and collaborated in university initiatives. Sonal has a keen interest in the personal professional development of educators and leaders in school systems. Her research areas include mindful and contemplative pedagogy, school culture, teacher identity, and teacher compassionate presence.

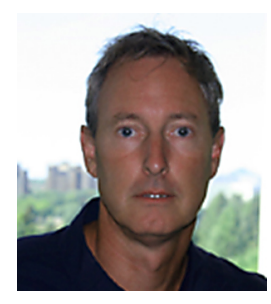

M. Shaun Murphy is Professor in Educational Foundations at the University of Saskatchewan. He was born and raised on Treaty Six territory, where he still works. He was an elementary school teacher in rural and urban settings for 20 years. Shaun's research interests are based in relational narrative inquiry, self-study of teacher practice, familial and school curriculum making; identity; rural education; assessment practices; the interwoven lives of children, families, and teachers; and teacher education. 